\title{
Tutorial \\ Development and Application of an Augmented Reality Oyster Learning System for Primary Marine Education
}

\author{
Min-Chai Hsieh
}

check for updates

Citation: Hsieh, M.-C. Development and Application of an Augmented Reality Oyster Learning System for Primary Marine Education. Electronics 2021, 10, 2818. https:// doi.org/10.3390/electronics10222818

Academic Editors: Osvaldo Gervasi and JungYoon Kim

Received: 9 October 2021

Accepted: 15 November 2021

Published: 17 November 2021

Publisher's Note: MDPI stays neutral with regard to jurisdictional claims in published maps and institutional affiliations.

Copyright: (C) 2021 by the author. Licensee MDPI, Basel, Switzerland. This article is an open access article distributed under the terms and conditions of the Creative Commons Attribution (CC BY) license (https:// creativecommons.org/licenses/by/ $4.0 /)$.
Department of Multimedia and Animation, Tainan University of Technology, Tainan 71002, Taiwan; shiehminchai@gmail.com

\begin{abstract}
Marine knowledge is such an important part of education that it has been integrated into various subjects and courses across educational levels. Previous research has indicated the importance of AR assisted students' learning during the learning process. This study proposed the AR Oyster Learning System (AROLS) that integrates mobile AR with a marine education teaching strategy for teachers in primary schools. To evaluate the effectiveness of the proposed approach, an experiment was conducted in a primary school natural science course regarding oysters. The participants consisted of 22 fourth-grade students. The experimental group comprised 11 students who learned with the AROLS learning approach and the control group comprised 11 students who learned with the conventional multimedia learning approach. The results indicate that (1) students were interested in the AR learning approach, (2) students' learning achievement and motivation were improved by the AR learning approach, (3) students acquired the target knowledge through the oyster course, and (4) students learned the importance of sustainability when taking online courses at home during the pandemic.
\end{abstract}

Keywords: augmented reality; marine education; oyster; picture book; teaching material design

\section{Introduction}

Marine education is a crucial issue included in the school curriculum in Taiwan. However, only a very small number of marine education courses are implemented as part of the formal school curriculum. The lack of these classes poses a threat. Although marine education is not an independent subject in the student's curriculum, other classes should integrate this content [1]. In Taiwan, the Ministry of Education published teaching materials on this subject since 2008 [2]. The knowledge in these publications is the blueprint for new classes and should have a bigger presence in Taiwanese education because of its actuality and importance. Teachers and environmental organizations of different levels strive to implement educational marine activities, providing opportunities for students and the general public to be close to the ocean and to understand it. In Taiwan, the ministry actively promotes mobile learning to upgrade the quality of teaching, enhance students' interest in studying, improve the effectiveness of teaching, and make classes more personalized. However, if the teacher uses simply technology without choosing a suitable learning strategy, the learning effect usually fails to meet the expectations [3]. The current research took place at a primary school in a district by the seaside in Tainan City in southern Taiwan. The district is known for its aquaculture-oyster farming. Oyster farming is an important part of marine education, and is an important highlight of education in this local context. The school-based curriculum at the target primary school features oyster-related marine education knowledge.

Teaching material has undergone significant changes, from traditional textbooks to digital media. The process of learning has become more vivid and rich. The use of multimedia-assisted learning can improve students' motivation and learning results. It shortens learning time and makes class more efficient [4,5]. Since the first half of 2021, 
Taiwan has been significantly affected by COVID-19. People have been confined by travel restrictions and study restrictions. Some have experienced financial struggles, been furloughed, or lost their jobs. Government agencies, corporate organizations, businesses, department stores, etc., have been affected. Schools are no exception. Schools have been closed since 19 May; students have to study at home until the summer vacation. It is of great concern to parents that learning from home may decrease students' learning effectiveness. Fortunately, due to the current development of AR virtual and real education applications, learning has become more interesting and helps promote the development of distance teaching programs. Learning through AR immersive technology will increase students' acceptance of new technologies. In addition, it provides parents with home learning solutions for school-age children. Learning has become more efficient, and is no longer restricted by time or space. Despite the pandemic, AR technology builds a virtual and real learning environment, in which students can interact with AR instead of merely staring at the screen and textbooks. Their motivation is elevated by the AR picture book and its lively interaction.

To evaluate the effectiveness of the approach proposed in this study, an experiment was conducted in a primary school natural science marine education course relating to oysters to examine the students' learning achievements and learning motivation. This study explored the usability of the AR Oyster Learning System (AROLS). The research questions were as follows:

- RQ1: Does an augmented-reality oyster learning system effectively improve fifth graders' knowledge about oysters in a marine education course?

- RQ2: Does an augmented-reality oyster learning system effectively increase fifth graders' learning motivation in a marine education course?

- RQ3: What are the perceptions of the course instructor and students about an augmentedreality oyster learning system for supporting marine education?

\section{Relevant Works}

\subsection{Theoretical Framework for the Study}

This study adopted the Substitution-Augmentation-Modification-Redefinition Model [6,7] as the framework to apply technology in the marine education curriculum at the target primary school (See Figure 1). Specifically, the Enhancement stage of the framework was realized by the AROLS. The system acts as a direct tool that substitutes traditional twodimensional storybook instruction on oyster farming with interactive features such as flipping a three-dimensional oyster upside down and enlarging or shrinking the oyster for close examination using AR technology.

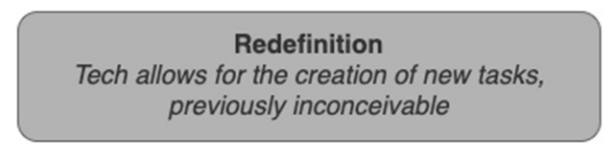

\section{Modification}

Tech allows for significant task redesign functional improvement change

Figure 1. The SAMR model [7]. 


\subsection{Augmented Reality}

Many AR, virtual reality (VR), and mixed reality (MR) technologies have been widely applied in education. For example, a virtual chemical laboratory has been applied to natural science in elementary education. The experiment consisted of a virtual experiment laboratory environment using AR cards [8]. Game-based learning studies combined with VR have also been conducted $[9,10]$. In addition to AR and VR, MR applications are becoming more common in education, such as MR applications in mechatronics education [11].

Everyone now has a mobile phone and can use AR applications without additional equipment. Among the AR, VR, and MR applications, AR has the lowest cost and is the easiest to use. AR features three characteristics: (a) combining real and virtual reality; (b) interacting in real time; and (c) viewing in 3D [12]. The types of AR trigger are markerbased AR, markerless AR, and location-based AR. Examples of marker-based AR are the fiducial marker and QR code, which people would recognize as a picture and, in general, is black. Markerless AR includes items such as a picture, image, poster, poster card, and business card. This is a natural feature, and people may not know that the picture is recognizable. Third, location-based AR is based on GPS for determining user locations and showing $2 \mathrm{D}, 3 \mathrm{D}$, and virtual information, superimposed on real environments by a mobile device [13]. In recent years, the application of AR has become increasingly widespread, and particularly the application of AR in education. Related research has shown a growing interest in studying the sustainability of AR in education [14]. AR is a computer graphic technology in which 3D virtual objects are immediately integrated into a 3D real environment [12]. AR applications in education have demonstrated significant value and advantages $[15,16]$.

In addition, AR has been gradually applied to many aspects of daily life, such as education, games, entertainment, navigation, social interaction, e-commerce, makeup, engineering, and medical [15,17-21]. AR is among the digital materials integrated into classrooms. Teachers use AR digital materials in class to help students reach a higher level of thinking by connecting with experiences in real world [5].

\subsection{The AR Picture Book}

The interactive mode of picture books has transformed significantly from traditional to digital, made the learning process more vivid and richer, and shortened the learning time, thus making learning more efficient [5]. Augmented reality focuses on the integration with the real world. It integrates virtual materials into the real world to achieve its interactive characteristics. The new interactive experience provided by AR has gradually entered the classroom. Grasset et al. reported on the design and development of a new type of mixed reality book, which added virtual visual and auditory enhancements to an already published book. The enhancements increased the users' immersion and allowed the user to interact with virtual objects in the mixed reality book when reading it [22].

Some studies have also reported that AR picture books can enhance students' learning interest. The AR picture book is attractive and evocative for children, and may be used as an effective learning tool to improve cognition of preschool children [23,24]. The AR applications in learning have become an increasing trend. However, there are few related studies that combine AR and picture books with marine education. Only one study has been conducted on children's learning interest in marine education by applying AR to children's educational products [25]. International research on using AR to support marine education also remains scarce. Thus, the study combined AR with marine education to design teaching materials and an AROLS about the oyster. In this approach, strategies for teaching about oysters are applied by the teachers, and students can learn in an AR-based interactive environment.

Based on the SAMR framework, this study utilized AR technology to achieve the augmentation level in the Enhancement Stage by creating a system that aims to create a three-dimensional AR presentation of an oyster's structure and breeding procedure, which was originally illustrated in a two-dimensional picture book. 


\section{The Development of the AR Oyster Learning System (AROLS)}

The researcher in this study designed and developed the AR Oyster Picture Book, designed the 2D and 3D digital contents, and developed an AR Oyster Learning System. The details of each component of this system are provided below.

\subsection{The AR Oyster Picture Book Design}

This study integrated the school-based curriculum of a primary school and designed an AR Oyster Picture Book. The AR Oyster Picture Book cover is shown in Figure 2. This oyster picture book is titled "Marine Education: Augmented Reality Oyster Legend". The graphic design process of the picture book included discussion, content data collection, composition design, watercolor drawing, scanning, toning, cropping, graphic layout, proofreading, printing, and attaching a hardcover. The AR Oyster Picture Book mainly guides students to understand the oyster farming environment, breeding methods, natural enemies, environmental damage and protection, and nutritional value of oysters. It is hoped that the local characteristic marine education curriculum will be modularized.

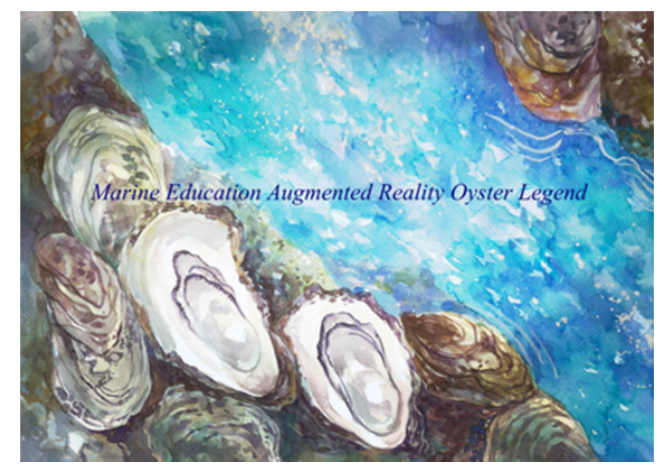

Figure 2. The AR Oyster Picture Book cover.

The marine education AR Oyster Picture Book underwent a systematic educational process to ensure its quality. It has a clear design to provide an effective strategy, to ensure correct content and teaching quality, and to ensure that the course conforms with the learning objectives in one learning experience. The design principle is based on the ADDIE (analysis-design-development-implementation and evaluation) analysis-model to ensure an effective class and space for development and improvement [26]. This study about AR applied to the marine education regarding oysters follows the ADDIE model. The five-step ADDIE research process is as follows:

- Analysis-Collect relevant information about AR and oyster marine education. Include learning targets, characteristics, teaching environments, existing resources, and students' background and their knowledge.

- Design-List the needs to incorporate AR into oyster marine education. Include augmented reality teaching materials, storyboards, teaching objectives, structures of textbooks, learning activities, evaluation methods, etc.

- Development-Infuse design content into the education and make a proposal. Include AR marine education oyster materials, develop materials, etc.

- Implementation - Integrate digital materials into the AROLS, and test its content by experimenting and implementing.

- Evaluation-Assess the quality and effectiveness of the implementation. Evaluate the student's perception to understand their responses, motivation, and learning curve.

One of the modules in the oyster textbook is "Knowing the ways of oyster farming", which explains the growth and harvest of oysters. In practice, the oysters that people usually consume are mostly supplied by the oyster farming. The whole process is similar to land-based farming, but, instead, an "oyster farm" is built in the ocean. Oyster farms are usually located at places with a wide and flat seabed. In Taiwan, many oyster farms can be 
found in the intertidal zone along the southwest coast of Tainan, the estuary near the ocean, and the lagoon. Various terrains result in distinct oyster farming methods. Moreover, Figure 3 shows the AR Oyster Picture Book content about knowing the ways of cultivating oysters. The pictures from left to right show four different oyster breeding methods: (a) floating shed type, (b) flat hanging type, (c) hanging type and (d) stone-stitched.

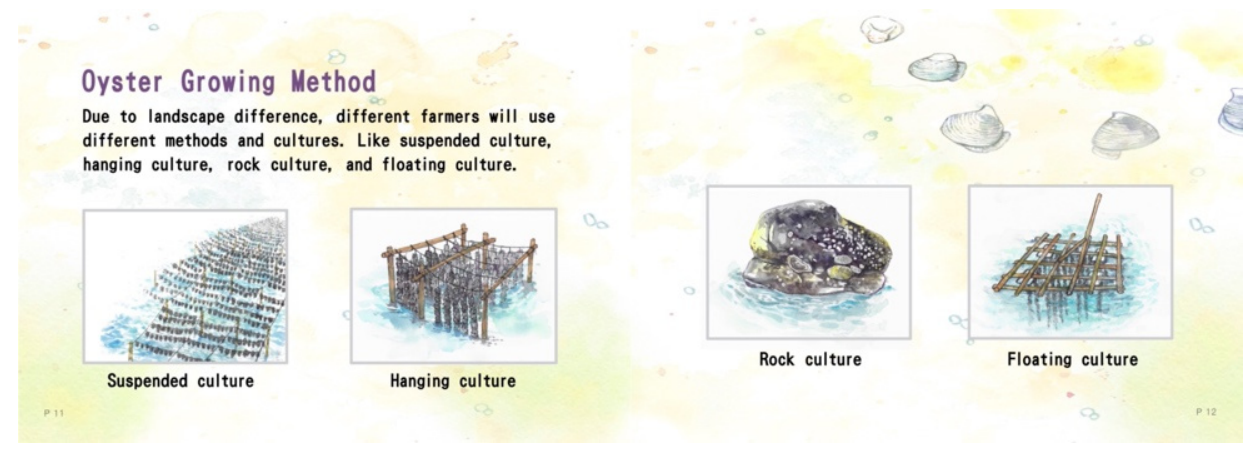

Figure 3. The AR Oyster Picture Book content-Knowing the ways of oyster farming.

(a) Floating shed type: Built in the open sea by using trusses and Styrofoam. Because the oysters are immersed in water all day, they can eat a lot, grow fast, and become softer in texture. This type farming can be found in the coastal areas of Anping in Tainan City.

(b) Flat hanging type: Suitable in shallow waters or intertidal zones. The oyster shells hang on trusses. This allows them to eat and grow at high tide, while low tide exposes them to the sun. The exposure to the sunshine for many hours improves their taste but also slows their growth.

(c) Hanging type: Suitable for growing in inner bays or tidal creeks. The shells are tied onto a string with a strong rope and hang in the seawater.

(d) Stone-stitching: This type involves oysters being cultivated in the wild (i.e., a closedoff area of the sea). Oysters can grow in naturally. Because there is no competition and sufficient space, the growth of the oysters is faster, and their size is larger. Giant oysters may be discovered.

\subsection{Digital Contents and 3D Modeling}

There are 26 pages in the AR Oyster Picture Book. The AR interaction digital content comprises thirteen pages. Twelve of these pages are $2 \mathrm{D}$ video digital learning contents, and one page comprises 3D model interaction digital content. The $2 \mathrm{D}$ video digital contents include texts, pictures, graphics, sound effects, narration, and subtitles.

The 3D model interaction digital content consists of 3D model scaling interaction and $3 \mathrm{D}$ rotation interaction. The $3 \mathrm{D}$ model interaction allows the user to use finger multi-touch gestures on the screen. The Blender software was used to build the 3D oyster model in this study. Blender is open-source 3D modeling software. In order to make the 3D oyster model resemble a real one, the researchers took an oyster picture in the oyster farm workplace. In the oyster 3D modeling, the oyster UV mapping (Figure 4) was used in order to present a realistic 3D model. The UV mapping is the 3D modeling process that involves projecting a 2D image onto a 3D model's surface for texture mapping. Figure 5 shows the realistic oyster 3D model rendering.

\subsection{The AR Oyster Learning System (AROLS) Development}

In this study, we developed an AR Oyster Learning System (AROLS). The Unity software and Vuforia SDK were used. Unity is the world's leading real-time 2D and $3 \mathrm{D}$ development platform. It can be used to develop AR, VR, 2D, 3D, and multimedia interaction applications for cross-platform use. Many other AR development tools are available, including Unreal Engine. In order to achieve optimal interactivity, Unity was 
chosen as the AR development tool in this study. Figure 6 presents the UML diagrams of AROLS and describes each class.

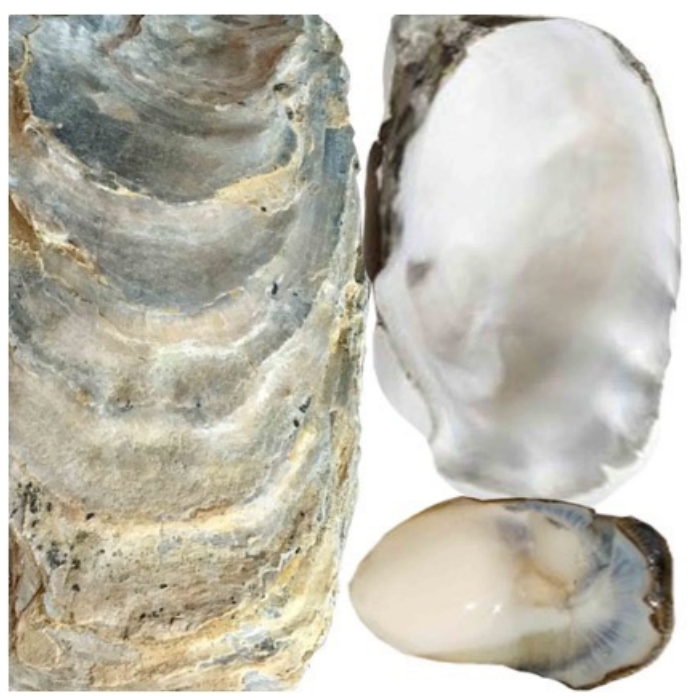

Figure 4. The oyster UV mapping (image textures).

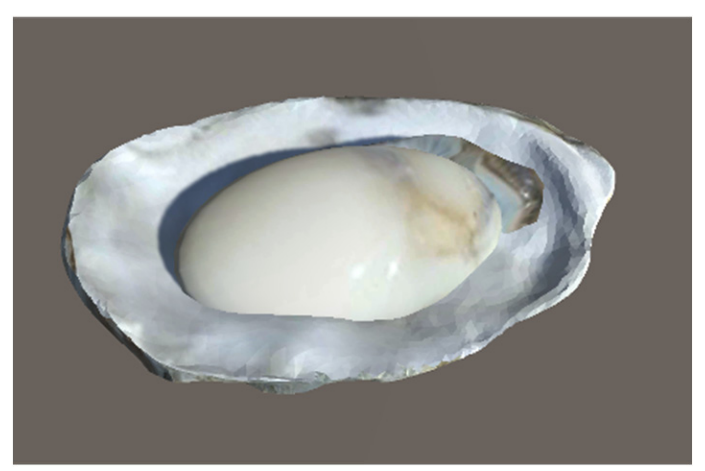

Figure 5. The oyster 3D model rendering.

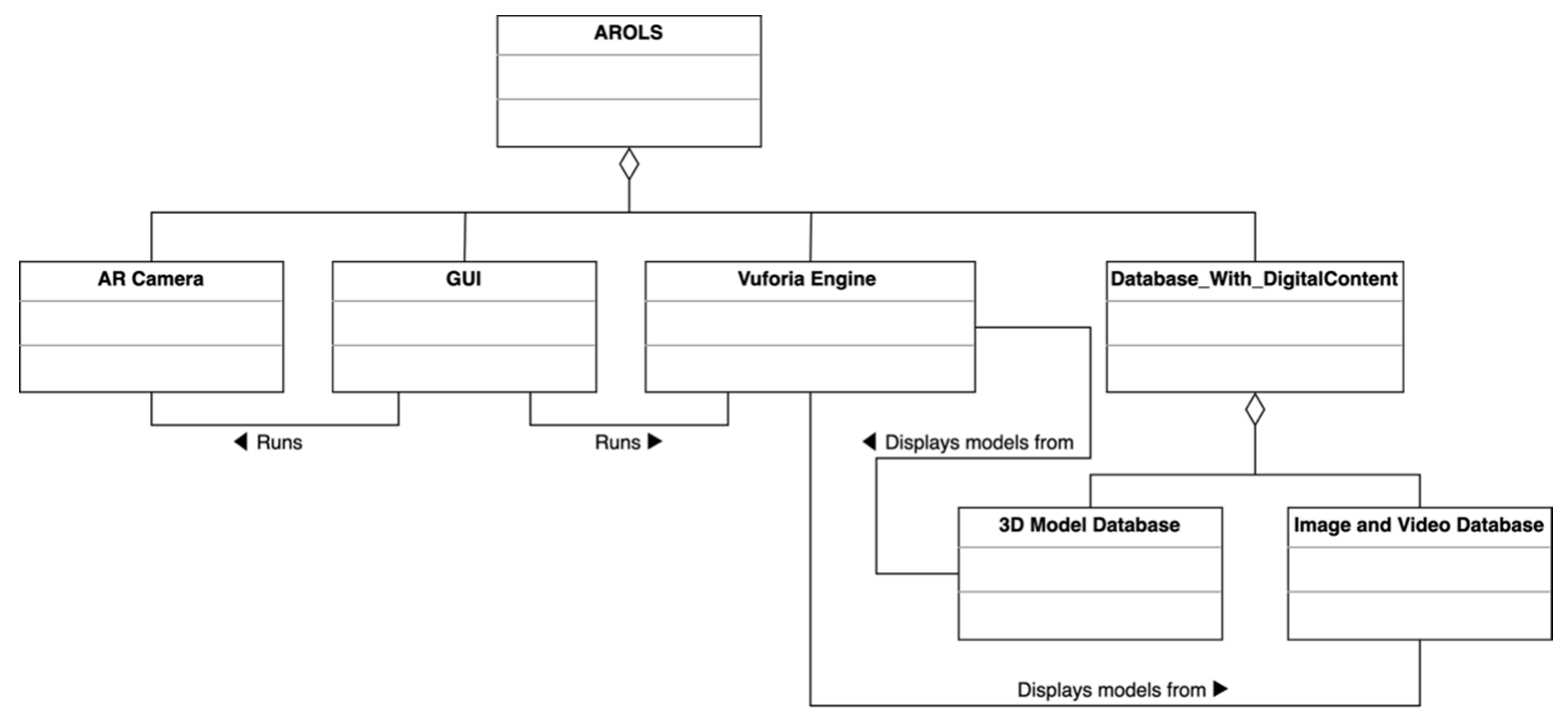

Figure 6. The UML class diagrams of AROLS. 
AROLS was developed using a mobile augmented reality tracking kit called Vuforia Engine. It is the most widely used AR development platform, and supports smart phones, tablets, and eyewear. The Vuforia Engine is a plug-in library that uses computer vision techniques to precisely overlay digital contents (3D model, video, picture, etc.) onto real world objects or scenery.

An AR camera is mainly used for updating and callback after AR has initialized. It detects each frame and determines whether there is an AR image. If an AR image is detected, it will display and redraw the digital contents on screen.

The system GUI can launch and switch the AR function. It defines control methods of the system interaction, e.g., scene switching, scaling, rotating, and moving. The user can interact with the 3D model with their hands when the AR content is displayed.

Class Database-With-Digital Content handles the import of the 3D model and digital contents. It includes a 3D Model Database and an Image and Video Database. The 3D Model Database reads static 3D model files, and the Image and Video Database reads images and videos files. In this study, the system uses Autodesk Filmbox format (FBX) models. It can be used and shared across a variety of content creation programs and digital modeling. FBX models are often used in animation, game development, and interaction application.

The graphical user interface of AROLS includes an interactive menu, interactive buttons, and other interactive features. Additional software applications were used for various elements:

- The videos: Adobe Premiere and Adobe after Effects for post-production of the video.

- $\quad 3 D$ Modeling: 3D modeling software Blender was used to design interactive 3D modeling.

- Picture book drawing and image design: Adobe Illustrator and Adobe Photoshop were used to design textbook images, the UI, Icons, the Splash Screen, oyster-related objects, the scenery, the interactive picture book, AR postcards, identification patterns, etc.

The AROLS development process was divided into three phases:

(a) First phase-discuss the content and planning the picture book. After completion, the animation design of the AR Oyster Picture Book was carried out.

(b) The second phase was classified into two parts: (i) 2D oyster knowledge animation, 3D oyster modeling, and AROLS prototype design; (ii) AROLS function and AR module development.

(c) Third phase-complete the AROLS development, test it, and launch it to Google Play and Apple App Stores. The AROLS is available for any users to download.

\section{Experimental Design}

\subsection{Participants}

The participants were 22 fourth-grade students from a primary school in southern Taiwan. The two classes were divided into two groups. One was the experimental group ( 6 boys and 5 girls) and the other was the control group ( 5 boys and 6 girls). In the experimental group, 11 students participated in the class with AR oyster teaching. In the control group, the other 11 students participated in the class with traditional oyster teaching without the assistance of AROLS. The same instructor taught the two classes. Every student had an iPad mini when learning in the classroom.

\subsection{Instrumentation}

The procedure of the experiment is shown as Figure 7. There were three parts in this experiment. In the first part, both groups learned the background knowledge of the oyster course taught by the teacher. Then, the students took a pretest in $30 \mathrm{~min}$ to assess their knowledge of oysters before participating in the experiment. In the second part, students in the experimental group used AR to assist their learning in the oyster course, whereas the control group students only used only multimedia materials consisting of the teacher's PowerPoint slides showing pictures of the oyster's structure and the two-dimensional picture book. The oyster course teaching and learning activity lasted eighty minutes in total. The mobile device screen displayed the AR content of the AR Oyster Picture Book. 
Each student used an iPad Mini to interact with the AR Oyster Picture Book by tapping the interactive buttons on the iPad screen with their finger. For example, as shown in Figure 8, when the student clicked on the interactive function button "Open", the shell of the oyster would open. When she clicked the interactive function button "Close", the shell of the oyster would close. Students could slide the screen to observe various parts of oyster. In the third part, after the leaning activity, both groups took a post-test. After the post-test, they filled out the questionnaire to measure their learning attitudes.

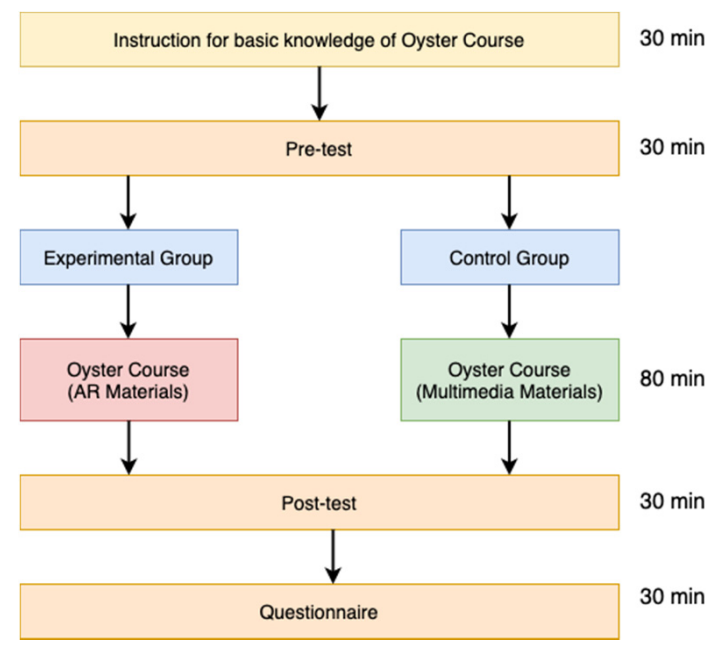

Figure 7. Experiment procedure flowchart.

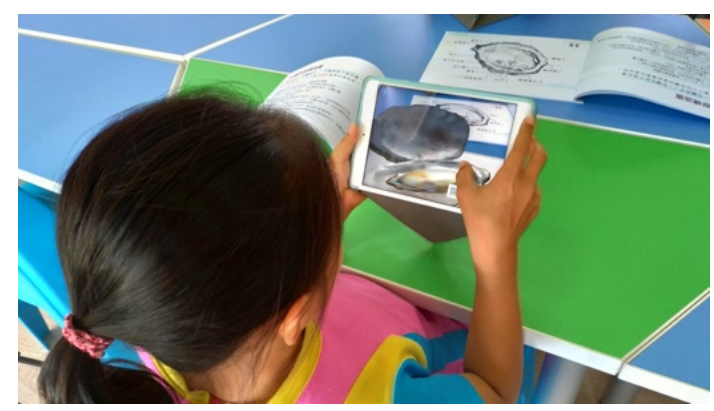

Figure 8. Picture book AR interaction during the learning activity (oyster opens).

\subsection{Measuring Tools}

The pre-test aimed to evaluate and understand the students' prior knowledge of oysters. The pre-test paper consisted of 19 multiple-choice items and 1 open-ended question. The total score was 100. The post-test, which was identical to the pre-test, aimed to evaluate the students' learning achievement after the intervention. Both tests were developed by a natural science teacher with five years of teaching experience.

The Instructional Materials Motivation Survey (IMMS), developed by Keller, was modified to assess students' learning motivation for the instructional materials. According to Keller, the ARCS is a motivation model, comprised of Attention, Relevance, Confidence, and Satisfaction [27]. ARCS integrates motivation theory and related theories. Motivation theory points out that if the teaching material developed by any kind of instructional design fails to arouse the learner's interest or focus, the effect of learning will be greatly decreased [28]. Therefore, this study adopted the IMMS as a measuring learning tool. The IMMS questionnaire used in the study was made up of 36 items with a five-point Likert scale. In addition, the questionnaire was reviewed by two experts to ensure content validity of the instrument. 


\section{Experimental Results}

\subsection{Learning Achievement}

In order to understand the difference between the experimental group before and after the experiment, the paired sample $t$-test was used to examine the differences between the pre-test scores and the post-test scores. To learn whether the experimental group's learning performance was improved due to the AR course, the pre-test and post-test grades were compared and examined via the paired sample $t$-test. The results shown in Table 1 indicate that in the experimental group, with the use of the AR materials, the mean score of the post-test (69.55) was higher than that of the pre-test (43.18). The post-test mean score was 26.37 higher than that of the pre-test mean score. The result of the paired sample $t$ test was $t=-6.336, p<0.05$. Thus, the students in the experimental group achieved a significant improvement in the oyster course after receiving the AR digital materials. In addition, the effect size Cohen's $d$ was 1.72, representing a large effect size [29].

Table 1. The paired sample $t$-test result of the students' learning achievement in experimental group toward oyster course learning.

\begin{tabular}{cccccc}
\hline $\boldsymbol{n}$ & Mean & SD & $t$ & $p$ & $d$ \\
\hline Pre-test (11) & 43.18 & 12.70 & -6.336 & $0.001^{*}$ & 1.72 \\
Post-test (11) & 69.55 & 17.53 & & \\
\hline * $p<0.05$ & &
\end{tabular}

${ }^{*} p<0.05$.

In order to understand whether the use of traditional multimedia boosted the learning achievement of the control group, the pre-test and post-test scores of the students in this group were also tested with paired sample $t$-tests. Table 2 shows that after the traditional teaching method, the students obtained a mean score of 63.18 in the post-test, 20.45 higher than that of the pre-test, which was 42.73. Based on the paired sample $t$ test result of $t=-4.230, p<0.05$, it can be seen that the control group students who received traditional teaching also exhibited significant progress in the mean scores of the pre-test and post-test. In addition, the effect size Cohen's $d$ was 1.61, representing a large effect size [29].

Table 2. The $t$-test results of the students' learning achievement in the control group for the oyster course learning.

\begin{tabular}{cccccc}
\hline $\boldsymbol{n}$ & Mean & SD & $\boldsymbol{t}$ & $\boldsymbol{p}$ & $\boldsymbol{d}$ \\
\hline Pre-test (11) & 42.73 & 12.32 & -4.230 & $0.002 *$ & 1.61 \\
Post-test (11) & 63.18 & 13.09 & & & \\
\hline${ }^{*} p<0.05$. & & & &
\end{tabular}

Regarding the between-group analysis, Table 3 shows the independent sample $t$-test result for the learning achievement of the two groups. The result showed a non-significant difference between the two groups $(t=0.96, p<0.05)$, with an effect size between small to medium $(d=0.41)$ [29]. There was no significant difference between the two groups in terms of learning achievement. However, the post-test scores of the students in the experimental group were 6.37 higher than those in the control group who received traditional teaching. The higher grades obtained by the experimental group implies that integrating AR materials into teaching can greatly improve students' learning achievements.

Table 3. The $t$-test result of the students' learning achievement score of the two groups.

\begin{tabular}{ccccccc}
\hline Group & $\boldsymbol{n}$ & Mean & SD & $\boldsymbol{t}$ & $\boldsymbol{p}$ & $\boldsymbol{d}$ \\
\hline Experimental group & 11 & 69.55 & 17.53 & \multirow{2}{*}{0.96} & 0.533 & 0.41 \\
Control group & 11 & 63.18 & 13.09 & & & \\
\hline
\end{tabular}




\subsection{Learning Motivation}

The experimental group and control group were contrasted to explore how the AR oyster teaching materials influenced students' learning motivation.

Table 4 demonstrates that the mean of the experimental group is higher than that of the control group in the Attention item $(4.08>3.84)$. Thus, the use of the AR Oyster Picture Book in the oyster course could attract the attention of students. In the Relevance item, the mean of the experimental group is also higher than that of the control group $(4.30>3.86)$. This shows that the use of the AR Oyster Picture Book could enable students to understand that learning is related to their own personal interests. It could further enhance learning motivation and connect students with prior knowledge and experience, so that students could continue to learn.

Table 4. Descriptive data of the IMMS results after oyster course.

\begin{tabular}{|c|c|c|c|c|c|c|c|}
\hline & & \multicolumn{2}{|c|}{ Experimental Group $(n=11)$} & \multicolumn{2}{|c|}{ Control Group $(n=11)$} & \multirow[b]{2}{*}{$t$} & \multirow[b]{2}{*}{$p$} \\
\hline & & Mean & SD & Mean & SD & & \\
\hline \multirow[b]{2}{*}{ Attention } & Positive item score & 4.08 & 0.955 & 3.84 & 0.868 & \multirow[t]{2}{*}{0.601} & \multirow[t]{2}{*}{0.555} \\
\hline & Negative item score & 1.35 & 0.420 & 1.60 & 0.429 & & \\
\hline \multirow{2}{*}{ Relevance } & Positive item score & 4.30 & 0.725 & 3.86 & 0.936 & \multirow[t]{2}{*}{1.209} & \multirow[t]{2}{*}{0.241} \\
\hline & Negative item score & 1.27 & 0.467 & 1.46 & 0.688 & & \\
\hline \multirow[b]{2}{*}{ Confidence } & Positive item score & 4.31 & 0.807 & 4.07 & 0.918 & \multirow[t]{2}{*}{0.642} & \multirow[t]{2}{*}{0.529} \\
\hline & Negative item score & 1.41 & 0.562 & 1.41 & 0.422 & & \\
\hline Satisfaction & Positive item score & 4.29 & 0.824 & 3.96 & 0.972 & 0.868 & 0.396 \\
\hline
\end{tabular}

The mean of the experimental group is also higher than that of the control group in the Confidence item (4.31 > 4.07). This result shows that the AR Oyster Picture Book could help students form a positive attitude, build confidence, and arouse their interest in learning. Finally, in the Satisfaction item, students in the experimental group generally agreed that the AR Oyster Picture Book could bring satisfaction, because their mean score was higher than that in the control group $(4.29>3.96)$. It may be inferred that AR Oyster Picture Book can constantly boost students' motivation. Although the independent sample $t$-test of the two groups in each item is not significant, overall, the study proves that using augmented reality as a learning aid can attract students' attention, strengthen their confidence, and finally give them satisfaction after learning.

\section{Discussion}

This study combined oyster teaching materials with an AR Oyster Picture Book to engage primary school children in marine knowledge acquisition. Using the ADDIE model, the AROLS was designed and developed to create additional effects to augment the traditional 2D picture book. After implementation and evaluation, the significant preversus post-test results proved that the AROLS not only achieved comparable effects to the 2D picture book approach, it also successfully achieved augmentation effects based on the SAMR model [6], thereby enhancing target learners' knowledge acquisition about oysters.

Many previous studies that utilized AR technology reported significant differences between the control and experimental groups [16,21]. Although the between-group statistical results did not show significant differences in this study, the experimental group did show more improvement in terms of the oyster knowledge test scores than the control group. In terms of students' learning motivation, although there was no significant between-group difference between the experimental and control groups in the survey results, the experimental group's responses showed better results in terms of the dimensions of Attention, Relevance, Confidence, and Satisfaction than the control group. For both the knowledge test and the survey, the small sample size ( $n=11$ in each group) may have led to the insignificant between-group differences. The sample size was therefore identified as a limitation of this study. 
The significant pre- versus post-test difference served as an indicator that the AROLS was as effective as traditional picture books. Post-intervention student feedback also indicated that the augmented digital contents provided by the AROLS not only allowed them to learn about the structure of an oyster in a more authentic way, but also it offered them an enriching opportunity to explore other parts of the picture book using the AR scanning functions on the system. This novel way of learning about oysters was attractive to them because they thought the oysters looked real through AR, and functions such as opening/closing and enlarging/shrinking the oyster aroused their curiosity about oysters.

As indicated by the course instructor in this study, the teaching and learning about oysters through the AROLS solved problems such as inconvenience of traveling to an oyster farm to see real oysters. Moreover, as a result of the use of the AROLS on mobile devices and portable picture books, students are able to engage in ubiquitous learning about oysters in formal (e.g., in classrooms) and informal (e.g., at home) settings [30]. Students could intuitively operate the iPad to engage in AR learning by scanning the picture book content to access the AR digital contents. This was a breakthrough for the teacher and students who often receive marine education in the traditional textbook-based learning mode. While using the AROLS, the researcher observed, with the exception of two students who seldom had access to mobile devices, most students were able to use the iPad and picture book smoothly, reflecting their familiarity with digital devices.

\section{Conclusions}

This study applied AR technology to design a set of marine education learning materials that consisted of an AR Oyster Picture Book and a mobile AR learning system. The study contributes to the field of marine education in the local context of Taiwan by designing and developing AROLS and making learning more convenient, efficient, and sanitary. Course instructors can not only use AROLS to engage learners in interacting with AR content about oysters without making a field trip to an oyster farm, they also can help learners engage in close-up examination of an oyster through the user-friendly AR affordances.

Students can use AROLS to study and gain an understanding of oysters. AROLS facilitates students' grasp of the content, enhancing their motivation and willingness to achieve better end-results in class, and even at home. AR assisted teaching can change traditional learning methods and can be integrated into many other subjects. This study was not about solving superficial problems but focused on academic research, which was tested in a school environment, and applied its results in an effective way. Due to the COVID-19 pandemic, AR picture books have played a much more crucial role in online learning. As long as students have the AR Oyster Picture Book and a mobile device, they can use AR to immediately learn oyster knowledge, build a connection with nature, and understand the importance of sustainability without going outside.

At present, this education system cannot record the behavior log of the learner's operation. In future study, we will develop log functions to record the learner's learning paths and log data so that learning behavior can be further analyzed. In addition, the research results will be promoted to other schools. The AROLS makes oyster education convenient for instructors and learning ubiquitous for students. In the future, the opinions of experts and teachers will be applied to modify and enhance AROLS. The final product can be translated to different languages and used in other counties.

Funding: Ministry of Science and Technology, Taiwan.

Institutional Review Board Statement: Not applicable. This project was executed and completed before the IRB policy initiated in Taiwan. So there was no IRB for this project.

Acknowledgments: We are grateful to the Tainan Municipal Simen Experimental elementary school students who participated in the study. This work was supported by the Ministry of Science \& Technology in Taiwan (MOST 107-2511-H-165-001).

Conflicts of Interest: Hsieh declares that there is no conflict of interest. 


\section{References}

1. Plunder or Perseverance? Children's Marine Education Cannot Wait. Available online: http://e-info.org.tw/node/200410\#4 (accessed on 5 January 2020).

2. Curriculum Guidelines of 12-Year Basic Education. Available online: https:// cirn.moe.edu.tw / WebNews/details.aspx?sid=11 \&mid=50\&nid=1618 (accessed on 5 August 2020).

3. Chu, H.C.; Hwang, G.J.; Tsai, C.C. A knowledge engineering approach to developing mindtools for context-aware ubiquitous learning. Comput. Educ. 2010, 54, 289-297. [CrossRef]

4. Wojciechowski, R.; Cellary, W. Evaluation of learners' attitude toward learning in ARIES augmented reality environments. Comput. Educ. 2013, 68, 570-585. [CrossRef]

5. Leighton, L.J.; Crompton, H. Augmented reality in K-12 education. In Mobile Technologies and Augmented Reality in Open Education; IGI Global: Hershey, PA, USA, 2017; pp. 281-290. [CrossRef]

6. Lyddon, P.A. A reflective approach to digital technology implementation in language teaching: Expanding pedagogical capacity by rethinking substitution, augmentation, modification, and redefinition. TESL Can. J. 2019, 36, 186-200. [CrossRef]

7. Puentedura, R.R. SAMR: A Brief Introduction. Available online: http://hippasus.com/rrpweblog/archives/2015/10/SAMR_ ABriefIntro.pdf (accessed on 15 September 2021).

8. Tsai, C.Y.; Ho, Y.C.; Nisar, H. Design and Validation of a Virtual Chemical Laboratory-An Example of Natural Science in Elementary Education. Appl. Sci. 2021, 11, 10070. [CrossRef]

9. Mayor, J.; López-Fernández, D. Scrum VR: Virtual Reality Serious Video Game to Learn Scrum. Appl. Sci. 2021, 11, 9015. [CrossRef]

10. Khan, N.; Muhammad, K.; Hussain, T.; Nasir, M.; Munsif, M.; Imran, A.S.; Sajjad, M. An Adaptive Game-Based Learning Strategy for Children Road Safety Education and Practice in Virtual Space. Sensors 2021, 21, 3661. [CrossRef] [PubMed]

11. Kucera, E.; Haffner, O.; Leskovský, R. Interactive and virtual/mixed reality applications for mechatronics education developed in unity engine. In Proceedings of the 2018 Cybernetics \& Informatics (K\&I), Lazy pod Makytou, Slovakia, 31 January-3 February 2018; pp. 1-5. [CrossRef]

12. Azuma, R.T. A survey of augmented reality. Presence Teleoperators Virtual Environ. 1997, 6, 355-385. [CrossRef]

13. 3 Different Types of AR Explained: Marker-based, Markerless \& Location. Available online: https://www.blippar.com/blog/20 18/08/14/marker-based-markerless-or-location-based-ar-different-types-of-ar (accessed on 2 November 2020).

14. Abad-Segura, E.; González-Zamar, M.D.; Luque-de la Rosa, A.; Morales Cevallos, M.B. Sustainability of Educational Technologies: An Approach to Augmented Reality Research. Sustainability 2020, 12, 4091. [CrossRef]

15. Robert, G.J. Augmented reality and language learning: From annotated vocabulary to place-based mobile games. Lang. Learn. Technol. 2016, 20, 9-19.

16. Lee, C.J.; Hsu, Y. Sustainable Education Using Augmented Reality in Vocational Certification Courses. Sustainability 2021, 13, 6434. [CrossRef]

17. Tang, S.L.; Kwoh, C.K.; Teo, M.-Y.; Sing, N.-W.; Ling, K.-V. Augmented reality systems for medical applications. IEEE Eng. Med. Biol. Mag. 1998, 17, 49-58. [CrossRef]

18. Rhee, H.L.; Lee, K.H. Enhancing the Sneakers Shopping Experience through Virtual Fitting Using Augmented Reality. Sustainability 2021, 13, 6336. [CrossRef]

19. Lin, V.; Lin, Y.H.; Hsieh, M.C.; Liu, G.Z.; Koong, H.C. The design and evaluation of a multimodal ubiquitous learning application for EFL writers. Digit. Creat. 2021, 32, 79-98. [CrossRef]

20. Lu, S.J.; Liu, Y.C.; Chen, P.J.; Hsieh, M.R. Evaluation of AR embedded physical puzzle game on students' learning achievement and motivation on elementary natural science. Interact. Learn. Environ. 2020, 28, 451-463. [CrossRef]

21. Hwang, G.J.; Wu, P.H.; Chen, C.C.; Tu, N.T. Effects of an augmented reality-based educational game on students' learning achievements and attitudes in real-world observations. Interact. Learn. Environ. 2016, 24, 1895-1906. [CrossRef]

22. Grasset, R.; Dünser, A.; Billinghurst, M. Edutainment with a mixed reality book: A visually augmented illustrative childrens' book. In Proceedings of the 2008 International Conference on Advances in Computer Entertainment Technology, Yokohama, Japan, 3-5 December 2008; pp. 292-295. [CrossRef]

23. Cheng, K.H.; Tsai, C.C. The interaction of child-parent shared reading with an augmented reality (AR) picture book and parents' conceptions of AR learning. Br. J. Educ. Technol. 2016, 47, 203-222. [CrossRef]

24. Yilmaz, R.M.; Kucuk, S.; Goktas, Y. Are augmented reality picture books magic or real for preschool children aged five to six? Br. J. Educ. Technol. 2017, 48, 824-841. [CrossRef]

25. Lu, S.J.; Liu, Y.C. Integrating augmented reality technology to enhance children's learning in marine education. Environ. Educ. Res. 2015, 21, 525-541. [CrossRef]

26. Molenda, M. In search of the elusive ADDIE model. Perform. Improv. 2003, 42, 34-37. [CrossRef]

27. Keller, J.M. Development and use of the ARCS model of instructional design. J. Instr. Dev. 1987, 10, 2-10. [CrossRef]

28. Keller, J.M. Strategies for stimulating the motivation to learn. Perform. Instr. 1987, 26, 1-7. [CrossRef]

29. Cohen, J. Statistical Power Analysis for the Behavioral Sciences, 2nd ed.; Lawrence Erlbaum Associates: Mahwah, NJ, USA, 1988.

30. Lin, V.; Liu, G.Z.; Hwang, G.J.; Chen, N.S.; Yin, C. Outcomes-based appropriation of context-aware ubiquitous technology across educational levels. Interact. Learn. Environ. 2019, 1-24. [CrossRef] 